Case Report

\title{
Rare presentation of subcutaneous panniculitis-like $T$ cell lymphoma in pediatric age group
}

\author{
Chandra Lekha T., Fathima Thahmi*, Nijaguna N., Sahana N. Srinivas
}

Department of Pediatrics, Indira Gandhi Institute of Child Health, Bangalore, Karnataka, India

Received: 30 August 2021

Accepted: 30 September 2021

\section{*Correspondence:}

Dr. Fathima Thahmi,

E-mail: chandralekhadr@gmail.com

Copyright: (c) the author(s), publisher and licensee Medip Academy. This is an open-access article distributed under the terms of the Creative Commons Attribution Non-Commercial License, which permits unrestricted non-commercial use, distribution, and reproduction in any medium, provided the original work is properly cited.

\begin{abstract}
Leukaemia and lymphoma are the commonly seen malignancies in children, subcutaneous panniculitis-like T-cell lymphoma (SPTL) is not only a rare cause of malignancy but also rare cause of panniculitis in children. We report an unusual presentation of this malignancy in the form of pyrexia of unknown origin (PUO), where rash was seen as very late symptom. Histopathology is seen as key in diagnosis of the disorder.
\end{abstract}

Keywords: Panniculitis, SPTL, Malignancy

\section{INTRODUCTION}

Inflammatory process in the subcutaneous adipose tissue is called panniculitis, rarely seen in children. ${ }^{1}$ Etiology of this can be infectious, physical, neoplastic or others. ${ }^{2}$ SPTL is a rare cause of panniculitis in general with incidence of $2.3-3 \%$ in Asian population. ${ }^{3}$ It is classified among cutaneous $\mathrm{T}$ cell lymphoma with indolent clinical behaviour as per world health organisation-European organization for research and treatment of cancer (WHOEORTC) classification of lymphoma. ${ }^{4}$

\section{CASE REPORT}

Herein we report a 11 years old female child who is second born to non-consanguineously married couple who presented with complaints of fever and joint pains since 6 months, abdominal distension, pedal edema and discolouration of the skin over abdomen and thigh since 15 days. After the initial 1 month of illness i.e., fever, the child was admitted and evaluated in a hospital, where was found to have pancytopenia, bone marrow aspiration showed no abnormality. Later as the child improved symptomatically was discharged home. Due to recurrence of symptoms, child was admitted in different hospital, where she was found to have hepatospleenomegaly along with pancytopenia, bone marrow aspiration was done thus for the second time suspecting leukaemia or HLH (hemophagocytic lympho histiocytosis), however showed no such evidence. Now child came to our hospital with persistent symptoms and new onset abdominal distension and skin discolouration over abdomen and outer part of thigh since 15 days, on examination child had pallor, generalised lymphadenopathy, pedal edema, genital edema and a peculiar rash over abdomen, bilateral upper $1 / 3$ of thighs which is red to purplish in colour and indurated on palpation as seen in Figure 1. Examination revealed generalised mild distension of abdomen with hepatosplenomegaly-liver span being $13 \mathrm{~cm}$ and spleen being $15 \mathrm{~cm}$. Thus, initial differentials were malignancyleukaemia/lymphoma, connective tissue disorders, chronic infections, human immunodeficiency virus (HIV).

Investigations revealed mild anaemia with haemoglobin being $9 \mathrm{gm} / \mathrm{dl}$, mild leukopenia with total counts-3200 cells/dl, 57\% polymorphs, absolute neutrophil count (ANC) 1824. Peripheral smear showed nutritional dimorphic anaemia with associated infection and mild leukopenia. Child also had hypoalbuminemia of serum albumin-1.8. Renal function tests, liver function tests, coagulation profile were within normal range. Sputum of 
cartridge-based nuclei acid amplification test (CBNAAT) was negative with negative Mantoux test. Tests suspecting autoimmune disorders such direct coombs test (DCT), anti-nuclear antibodies (ANA), double stranded DNA (dsDNA) were done and were negative. As most of our differentials were ruled out with these non-invasive tests, previous bone marrow slides were reviewed and revealed no significant information. Meanwhile the child was stabilised and monitored during hospital stay where she continued to have fever spikes not responding to conventional antipyretics, also there was increase and persistence of the rash which was very peculiar, with the help of pediatric dermatology team skin biopsy was performed which showed: peri vascular and peri-adnexal lymphocytic infiltrates in dermis, subcutis showed scattered atypical lymphoid cells involving the fat lobules. Immunohistochemistry for CD8, granzyme, CD3 CD4, KI 67 was positive, thus confirming the diagnosis as cutaneous $\mathrm{T}$ cell lymphoma.

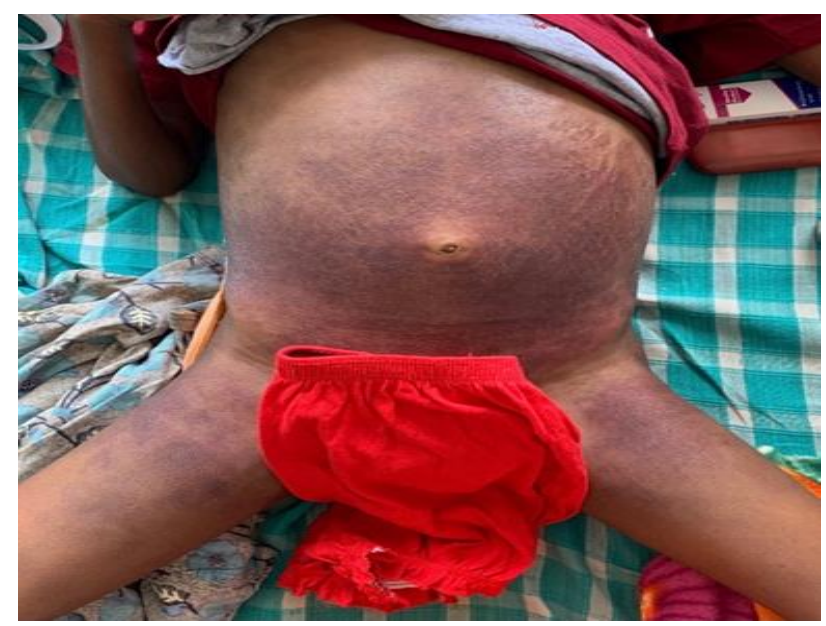

Figure 1: Pallor, generalised lymphadenopathy, pedal edema, genital edema and a peculiar rash over abdomen.

\section{DISCUSSION}

Leukaemia and lymphoma are the common malignancies among children, and $60 \%$ of the lymphoma are NHL. ${ }^{5}$ $50 \%$ of non-Hodgkin's lymphoma (NHL) are $\mathrm{T}$ cell derived in pediatric age group. ${ }^{6}$ Skin is the second most common extra-nodal site of NHL, counting to about $4 \%$ of NHL. ${ }^{7}$ Over all incidence of cutaneous $\mathrm{T}$ cell lymphoma (CTCL) is 6 per million, although less in children; all ages can be affected.

WHO-EORTC has classified CTCL into various types based on their clinical manifestations. SPTL is a rare CTCL in children but a distinct type with infiltration of mature malignant $\mathrm{T}$ cells in subcutaneous adipose tissue resulting in panniculitis. ${ }^{8-10}$ The average age of presentation is 36 years with female predominance, children typically present with fever and multiple or solitary skin nodules or plaques which are erythematous seen in trunk or extremities. ${ }^{11,12}$ Thus our case differs from the typical presentation of SPTL in age of presentation as well as skin involvement which is seen only after 6 months of the initial complaint. The immunophenotype characteristic for SPTL includes CD3p, CD4-. CD8p, CD56- and $\beta F-1 p$ which were all present in the biopsy specimen of our patient. ${ }^{13}$ An elliptical punch biopsy of adequate size and depth of the involved subcutaneous adipose tissue is the ideal specimen to be obtained for histopathological assessment. $^{1,2}$ Dermatology team was very crucial in diagnosing our case. The earlier the biopsy, more specific are the changes. ${ }^{2}$ In general they have a good prognosis especially in absence of HLH where the survival is about $80 \% .{ }^{12,13}$ After diagnosis our patient has been started on cyclophosphamide, hydroxydaunorubicin, oncovin and prednisone (CHOP) regimen which showed results in the form of resolution of rash and subsidence of fever with 2 weeks.

\section{CONCLUSION}

In cases where diagnosis is in dilemma, high index of suspicion is necessary to suspect and identify SPTL. As specific guidelines to define, diagnose pediatric panniculitides are not well established, histopathological examination is vital for early diagnosis and avoid further complications if left untreated.

Funding: No funding sources Conflict of interest: None declared Ethical approval: Not required

\section{REFERENCES}

1. Torrelo A, Hernandez A. Panniculitis in children. Dermatol Clin. 2008;26(4):491-500.

2. Polcari IC, Stein SL. Panniculitis in childhood. Dermatol Ther. 2010;23(4):356-67.

3. Tee Evelyn Wy Yap CT, Evelyn Yap WY. Not all swellings are lymph nodes! A case of subcutaneous panniculitis-like T-cell lymphoma. Med J Malaysia. 2019;74(5):441-2.

4. Ceppi F, Pope E, Ngan B, Abla O. Review Primary Cutaneous Lymphomas in Children and Adolescents. Pediatr Blood Cancer. 2016;63(11):1886-94.

5. Murphy SB. Classification, staging and end resubs of treatment of childhood non-Hodgkin's lymphomas: dissimilarities from lymphomas in adults. Semin Oncol. 1980;7:332-9.

6. Bernard A, Murphy SB, Meivin S. Non-T, non-B lymphomas are rare in childhood and associated with cutaneous tumor. Blood. 1982;59:549-554.

7. Imam MH, Shenov PJ, Flowers CR. Incidence and survival patterns of cutaneous T-cell lymphomas in the United States. Leukemia Lymphoma. 2013;54(4):752-9.

8. Ohtsuka M, Miura T, Yamamoto T. Clinical characteristics, differential diagnosis, and treatment outcome of subcutaneous panniculitis-like T-cell 
lymphoma: a literature review of published Japanese cases. Eur J Dermatol. 2017;27(1):34-41.

9. Kawachi Y, Furuta J, Fujisawa Y, Nakamura Y, Ishii Y, Otsuka F. Indolent subcutaneous panniculitis-like $\mathrm{T}$ cell lymphoma in a 1-year-old child. Pediatr Dermatol. 2012;29(3):374-7.

10. Parveen Z. Subcutaneous panniculitis-like T-cell lymphoma redefinition of diagnostic criteria in the recent World Health Organization-European Organization for research and treatment of cancer classification for cutaneous lymphomas. Arch Pathol Lab Med. 2009;133:303-8.

11. Willemze R, Jansen PM, Cerroni L, Berti E, Santucci $\mathrm{M}$, Assaf $\mathrm{C}$ et al. Subcutaneous panniculitis-like Tcell lymphoma: definition, classification, and prognostic factors: an EORTC Cutaneous
Lymphoma Group Study of 83 cases. Blood. 2008;111(2):838-45.

12. Hu ZL, Sang H, Deng L, Li Z. Subcutaneous panniculitis-like T-cell lymphoma in children: a review of the literature. Pediatr Dermatol. 2015;32(4):526-32.

13. Willemze R, Cerroni L, Kempf W, Berti E, Facchetti F, Swerdlow SH et al. The 2018 update of the WHOEORTC classification for primary cutaneous lymphomas. Blood. 2019;133(16):1703-14.

Cite this article as: Lekha $\mathrm{CT}$, Thahmi F, Nijaguna N, Srinivas SN. Rare presentation of subcutaneous panniculitis-like $\mathrm{T}$ cell lymphoma in pediatric age group. Int J Contemp Pediatr 2021;8:1902-4. 